\title{
Arsenic (III) Biosorption with Fenugreek (Methi) Seed Powder as a Low-cost Biosorbent
}

\author{
Vijayarani Allam ${ }^{1,}$, , Sailaja Budati Bala Venkata ${ }^{1}$, Sirisha David ${ }^{2}$ \\ ${ }^{1}$ Department of Inorganic and Analytical Chemistry, Andhra University, Visakhapatnam, India \\ ${ }^{2}$ Department of Chemistry, St. Ann's Degree College for Women, Osmania University, Hyderabad, India
}

Email address:

sr.vijayarani.allam@gmail.com (V. Allam)

*Corresponding author

\section{To cite this article:}

Vijayarani Allam, Sailaja Budati Bala Venkata, Sirisha David. Arsenic (III) Biosorption with Fenugreek (Methi) Seed Powder as a Low-cost Biosorbent. American Journal of Chemical and Biochemical Engineering. Vol. 5, No. 1, 2021, pp. 26-31. doi: 10.11648/j.ajcbe.20210501.14

Received: May 4, 2021; Accepted: May 21, 2021; Published: May 27, 2021

\begin{abstract}
This research study focuses at the use of fenugreek seed powder as a bio adsorbent for removing arsenic from aqueous media. Metal biosorption research on Fenugreek seed powder has been studied in just a few studies. SEM, FTIR, and XRD were used to investigate the constituents and properties of fenugreek seed powder, which revealed the constituents and properties that enabled the arsenic biosorption process to succeed. To investigate the strength of arsenic adsorption using Fenugreek seed powder as a bioadsorbent, the effects of primary parameters including contact time, dose, concentration, $\mathrm{pH}$, and temperature were used. The report of these parameters suggested that as the parameters increased, the efficient removal of arsenic increased until equilibrium was reached, but no successful results were seen after gaining the equilibrium. The biosorption process to Freundlich isotherm and pseudo kinetic order in liner form with better correlation coefficients was verified by a survey of biosorption isotherms and kinetic results. The system was endothermic, random, and favourable with biosorption characteristics at various temperatures, as determined by the thermodynamic constants. As a result of these findings, fenugreek seed powder has been modified for arsenic adsorption.
\end{abstract}

Keywords: Arsenic, Fenugreek, Biosorption, Isotherms, Kinetic Order, Thermodynamics

\section{Introduction}

The continued emission of contaminants is causing a largescale destruction of the natural environment, which is a major social problem that has diverted people's attention away from basic human needs. The various factories in Hyderabad, where my research is taking place, produce a large amount of inorganic metals, which are then discharged into the water supply, where they are consumed by the people in the region, resulting in a variety of diseases and deaths. Arsenic is one of those inorganic compounds that have a significant toxicological impact on human life. Toxicological profiles for arsenic elements have been included in standard texts [1] and government findings [2-4] referring to the illustration of arsenic's toxico kinetics and toxicity. The aim of this study is to aim at the health risks that arsenic pollution in water can cause.

\subsection{Characterization of Fenugreek Seed Powder}

The hydrophobic and hydrophilic properties of cellulose, hemicellulose, and lignin are found in fenugreek seed powder. The FTIR spectrum detects adsorption bands such as $\mathrm{C}-\mathrm{H}, \mathrm{C}=\mathrm{C}, \mathrm{C}-\mathrm{O}, \mathrm{C}-\mathrm{N}, \mathrm{O}-\mathrm{H}, \mathrm{N}-\mathrm{H}$ (primary amines), and C-O$\mathrm{H}$. At higher temperatures, the carbonyl group releases $\mathrm{CO} 2$, which causes these bands to vanish $(4000 \mathrm{oC})$. The presence of hetero atoms $(\mathrm{N}, \mathrm{O})$ and some bonds on the surface of the biosorbent are thought to be involved in the biosorption process, and thus Fenugreek seed powder can be used as a biosorbent.

Alkaloids, amino acids, saponins, steroidal sapinogens, flavonoids, fibres, and lipids such as triacylglycerols, diacylglycerols, monoacylglycerols, and free fatty acids 1 are also present and may support with the biosorption process $[5]$.

\section{Results and Discussion}

\subsection{Contact Time's Effect}

The biosorption of arsenic with 1 gm of Fenugreek powder 
varies with contact time from 10 to 50 minutes, as shown in Figure 1. From 10 to 20 minutes later, there is a sharp increase in biosorption, followed by a sharp decline. In the rate of Arsenic biosorption, there is a noticeable difference. Due to the presence of more active sites on the surface of the biosorbent, the rate of biosorption is high in the early stages. For Arsenic, the maximum biosorption time is 20 minutes. Since there are n't enough vacant places on the biosorbent after 20 minutes, the grade of biosorption would most likely decrease. As a result, biosorption appears to be decreasing, and this trend continued until the end of the contact period analysis [6].

\subsection{Dosage Estimation}

The arsenic biosorption potential is tested using a $50 \mu \mathrm{g} / \mathrm{L}$ Arsenic concentration and varying dosages of Fenugreek at a 20 -minute contact period. The rate of biosorption is predominant, denoting $65 \%$ arsenic removal at 2 gm of Methi powder dosage, owing to the greater accessibility of sorption sites on biosorbent. This proximity is retained until $3.5 \mathrm{gm}$, and then the arsenic biosorption is progressively diminished due to the overlaying of the biosorbent particles on the sites, as shown in Figure 2 [7, 8].

\subsection{Initial Arsenic Concentration}

Lower Arsenic concentrations of $10 \mu \mathrm{g} / \mathrm{L}$ to $30 \mu \mathrm{g} / \mathrm{L}$ as Arsenic metal ion had the lowest biosorption potential. In lower initial Arsenic concentrations $(10 \mu \mathrm{g} / \mathrm{L}$ to $40 \mu \mathrm{g} / \mathrm{L})$, the ratio of Arsenic metal ions to Fenugreek mass is low. As a result, the functional groups present in Methi powder occupied the binding sites of Arsenic metal, resulting in a higher Arsenic removal percentage. Additional metal ions were inferred with an increase in initial concentration, i.e., above $40 \mu \mathrm{g} / \mathrm{L}$ these ions are adhered to the same quantity of Fenugreek powder, causing saturation of the biosorbent, resulting in a decrease in percent removal, as shown in Figure 3.

In order to resolve the mass transfer opposition for the movement of metal ions from the mixture to the adsorbent surface, the saturation of the biosorbent surface may occur at higher concentrations as the driving force increases [9].

\subsection{The Function of PH for Arsenic Biosorption onto Methi}

At $\mathrm{pH} 4.0$, arsenic biosorption was highest. As shown in Figure 4 , there was a steady rise in $\mathrm{pH}$ between 2.0 and 4.0 and from $\mathrm{pH} 4.0$ to 10.0 there was a decrease in arsenic biosorption. The concentration of counter ions on the functional groups of fenugreek powder such as Alkaloids, Amino acids, Saponins, and others, as well as the degree of ionisation of the biosorbate during reaction, is influenced by $\mathrm{pH}$. The same conclusions were reached by all of the participants $[10,11]$.

\subsection{Temperature Effects on Methi Biosorption}

As shown in Figure 5, changing the temperature from $20^{\circ} \mathrm{C}$ to $80^{\circ} \mathrm{C}$ influenced Arsenic biosorption using fenugreek powder. The chemical components of the biosorbent and metal ions gradually bonded up from low to high temperatures, resulting in efficient arsenic absorption and the mobility of the Arsenic metal ions due to their higher kinetic energies. The rate of biosorption was also affected by the increase in pore volume of the biosorbent [12].

\subsection{Biosorption Isotherms of Langmuir, Freundlich, and Temkin}

The application of biosorption isotherm models of Langmuir, Freundlich, and Temkin senses the strength of Arsenic biosorption in their phrases [13, 14]. The biosorption capacities are also depicted on the isotherms, which scan the interactions of adsorbate molecules with the adsorbent surface.

The $R_{2}$ values 0.998-0.989 for Langmuir, 0.954-0.997 for Freundlich, and 0.906-0.972 for Temkin generated from the slope and intercept by the plot of log qe vs log ce depicted Figure 7 that $R_{2}$ values $0.954-0.997$ for Freundlich, are higher than Langmuir and Temkin, which denote the highest correlation coefficient values as per the records of our study in Table 1. The experimental data was well demonstrated by the Freundlich isotherm.

The negative values of $Q_{0}$ in Langmuir and low $R_{2}$ in Temkin did not shed light on the Arsenic biosorptin, according to the Temkin and Langmuir plots in Figure 6 and Figure 8 and according to Table 1 .

\subsection{Kinetic Biosorption Studies}

In this study, the activity of biosorption was investigated by fitting kinetic parameters to realistic data, such as pseudo first and second order kinetics, Elovich, and intraparticle diffusion models. Arsenic biosorption could not follow the Pseudo first order, according to the equation [15]. Since it is nonlinear as shown in Figure 9 and $\mathrm{R}_{2}$ values are tiny, as shown in Table 2 the arsenic experimental data was not apt to the Langmuir isotherm.

The slope and intercept of the plot of $t / q t$ versus $t$ that can be seen in Figure 10 were used to estimate the pseudo second order kinetic rate constants $\mathrm{k}_{2}$ and qe at various temperatures. The calculated qe values agree with experimental qe values, and $R_{2}$ values $(0.971)$ were higher than other kinetic parameters, as shown by the results of $\mathrm{k}_{2}$ and qe seen in Table 2. The linear form, which is experimental proof, revealed that Arsenic biosorption is apt to the Pseudo second order kinetic and fit well to the data, with the same results recorded by Figure 10 [16].

Table 3 and Figures 11 and 12 show that the experimental results from Arsenic biosorption on Fenugreek powder did not match well with the Elovich and Intraparticle diffusion models.

\subsection{A Retrospective of Thermodynamics and Equilibrium}

The values of the thermodynamic parameters $\Delta \mathrm{H}^{\circ}, \Delta \mathrm{S}^{\circ}$, and $\Delta \mathrm{G}^{\circ}$ were determined from an analysis of Arsenic biosorption at different temperatures $\left(20^{\circ}\right.$ to $\left.80^{\circ} \mathrm{C}\right) . \Delta \mathrm{G}^{\circ}$ was calculated using the Langmuir equilibrium constant $[17,18]$. The Vont's Hoff equation can be used to measure the 
enthalpy and entropy of the biosorption process:

$$
\ln \mathrm{K}=\frac{\Delta H^{\circ}}{R T}+\frac{\Delta S^{\circ}}{R}
$$

(1) The following equation was used to calculate the activation energy $\left(E_{a}\right)$;

$$
E_{\mathrm{a}=\Delta \mathrm{H}^{\circ}}+R T
$$

(2) Positive values of $\Delta \mathrm{H}^{\circ}$ and $E_{a}$ suggest that adsorption is an endothermic mechanism that absorbs energy from the surroundings, as shown in Table 3 and Figure 13. The presence of orderliness in the biosorption process was indicated by the negative values of $\Delta \mathrm{S}^{\circ}$. The favourable and spontaneous essence of Arsenic biosorption is shown by the negative value of $\Delta \mathrm{G}^{\circ}$, which decreased as temperature increased.

(3) The separation factor, $\mathrm{R}_{\mathrm{L}}$ is calculated from the equation:

$$
R_{L}=\frac{1}{1+b C_{o}}
$$

with $\mathrm{C}_{\mathrm{o}}$ denoting the adsorbate's initial concentration. The isotherm's form is either linear $\left(R_{L}=1\right)$, irreversible $\left(R_{L}=0\right)$, or favourable $\left(0<R_{L}<1\right)$ [19] as indicated by the $R_{L}$ value. If the $\mathrm{R}_{\mathrm{L}}$ value is between 0 and 1 , the adsorption process is likely to be favourable. The Arsenic biosorption on Fenugreek powder is a favourable method, according to the

\begin{tabular}{|c|c|c|c|c|c|c|}
\hline S. No & Parameters & Temki & Isotherr & & & \\
\hline \multirow{5}{*}{01.} & Temperature ${ }^{\circ} \mathrm{C}$ & 0 & 20 & 40 & 60 & 80 \\
\hline & $\mathrm{R}^{2}$ & 0.906 & 0.940 & 0.950 & 0.952 & 0.972 \\
\hline & ASS & 0.048 & 0.030 & 0.025 & 0.024 & 0.014 \\
\hline & $\mathrm{a}_{\mathrm{T}}$ & 0.195 & 0.224 & 0.256 & 0.280 & 0.326 \\
\hline & $\mathrm{b}_{\mathrm{T}}$ & 0.991 & 1.913 & 0.966 & 1.017 & 0.920 \\
\hline \multirow{4}{*}{02.} & \multicolumn{6}{|c|}{ Langmuir Adsorption Isotherm } \\
\hline & $\mathrm{R}^{2}$ & 0.997 & 0.998 & 0.995 & 0.989 & 0.985 \\
\hline & $\mathrm{a}_{\mathrm{T}}$ & -0.005 & -0.004 & -0.004 & -0.005 & -0.004 \\
\hline & $\mathrm{b}_{\mathrm{T}}$ & 0.415 & 0.422 & 0.465 & 0.499 & 0.519 \\
\hline \multirow{5}{*}{03.} & \multicolumn{6}{|c|}{ Freundlich Adsorption Isotherm } \\
\hline & $\mathrm{R}^{2}$ & 0.954 & 0.984 & 0.992 & 0.988 & 0.997 \\
\hline & ASS & 0.001 & 0.000 & 0.000 & 0.000 & 0.000 \\
\hline & $\mathrm{a}_{\mathrm{T}}$ & 0.530 & 0.600 & 0.615 & 0.634 & 0.697 \\
\hline & $\mathrm{b}_{\mathrm{T}}$ & 0.075 & 0.017 & 0.048 & 0.016 & 0.016 \\
\hline
\end{tabular}
$\mathrm{R}_{\mathrm{L}}$ (Table 4 and Figure 14) results.

Table 1. Adsorption isotherm constant and statistical comparison values of adsorption isotherm models for Arsenic adsorption by Fenugreek powder.

Table 2. Kinetic parameters for adsorption of Arsenic by Fenugreek powder.

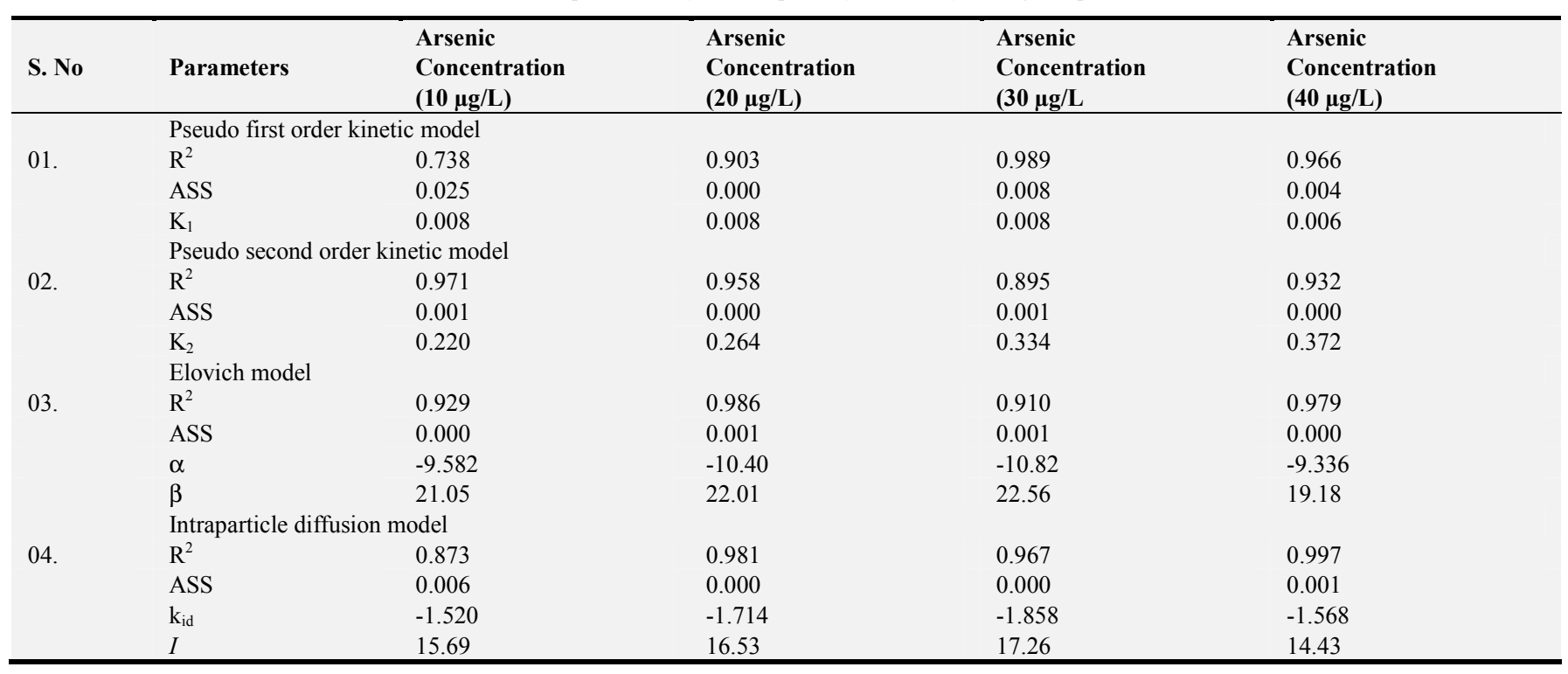

Table 3. Thermodynamic parameters of Arsenic adsorption by Methi powder.

\begin{tabular}{llll}
\hline S. No & Temperature & $\Delta \mathbf{G}(\mathbf{K J} / \mathbf{m o l})$ & $\Delta \mathbf{S}(\mathbf{K J} / \mathbf{m o l})$ \\
\hline 1. & $273 \mathrm{~K}$ & -61.28 & -21.42 \\
2. & $293 \mathrm{~K}$ & -53.59 & \\
3. & $313 \mathrm{~K}$ & -57.25 & \\
4. & $333 \mathrm{~K}$ & -55.37 & \\
\hline
\end{tabular}




\begin{tabular}{lllll}
\hline S. No & Temperature & $\Delta \mathbf{G ~ ( K J / m o l )}$ & $\Delta \mathbf{S}(\mathbf{K J} / \mathbf{m o l})$ & $\Delta \mathbf{H}(\mathbf{K J} / \mathbf{m o l})$ \\
\hline 5. & $353 \mathrm{~K}$ & -49.89 & \\
\hline
\end{tabular}

Table 4. Equilibrium parameter $R_{L}$ values at different concentrations and temperatures.

\begin{tabular}{|c|c|c|c|c|}
\hline \multirow{2}{*}{ S. No } & \multirow{2}{*}{ Temperature $\left({ }^{\circ} \mathrm{C}\right)$} & \multicolumn{3}{|c|}{ Concentration of Arsenic $(\mu \mathrm{g} / \mathrm{L})$ and $R_{L}$ values } \\
\hline & & $10 \mu \mathrm{g} / \mathrm{L}$ & $30 \mu \mathrm{g} / \mathrm{L}$ & $50 \mu \mathrm{g} / \mathrm{L}$ \\
\hline 01. & 0 & 0.1005 & 0.033 & 0.200 \\
\hline 02. & 20 & 0.1004 & 0.033 & 0.200 \\
\hline 03. & 40 & 0.1004 & 0.033 & 0.200 \\
\hline 04. & 60 & 0.1005 & 0.033 & 0.200 \\
\hline 05. & 80 & 0.1004 & 0.033 & 0.200 \\
\hline
\end{tabular}

Methi

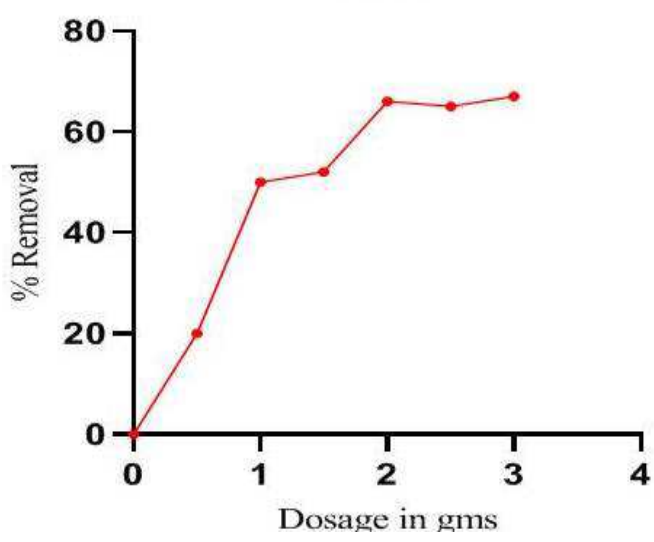

Figure 1. Contact time varies with biosorption of arsenic.

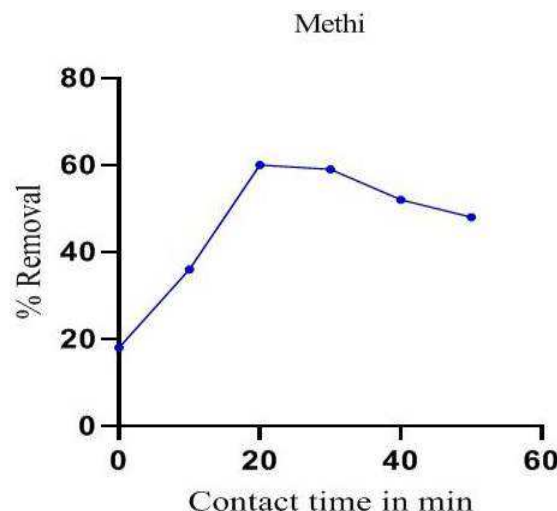

Figure 2. Differential Arsenic Absorption capabilities at Different Doses.

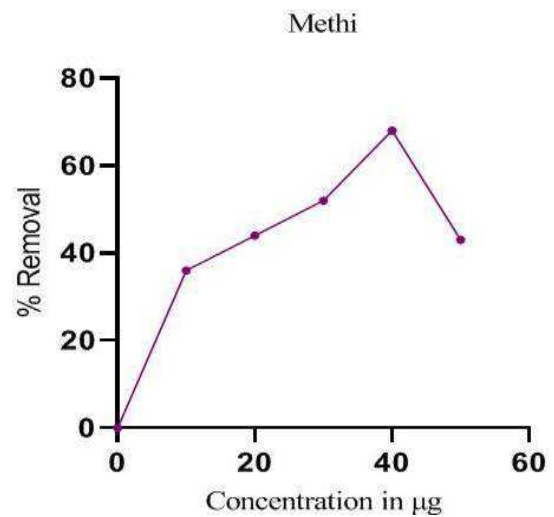

Figure 3. The effect of different levels of arsenic on Methi powder.

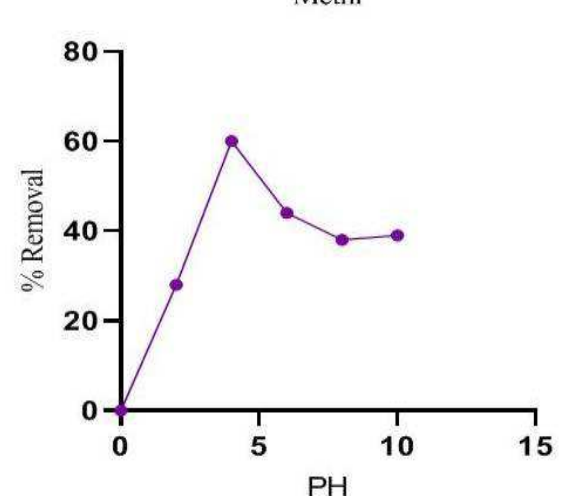

Figure 4. Arsenic biosorption on Methi as a feature of $\mathrm{pH}$.

Methi powder

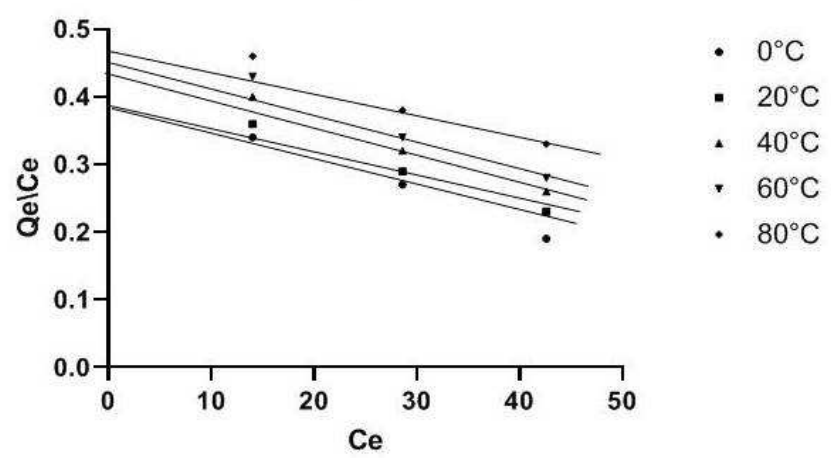

Figure 5. Impact of temperatures on by the Langmuir Isotherm.

Adsorption of Methi

at various temperatures

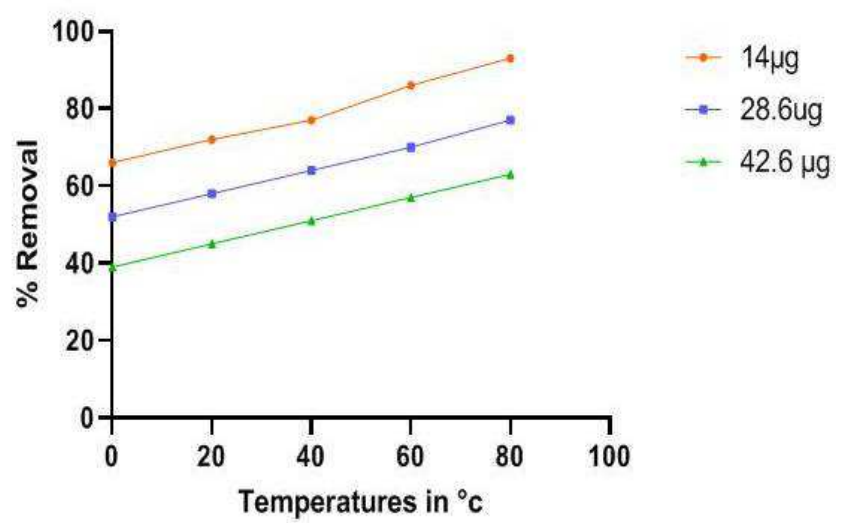

Figure 6. Shows the elimination of arsenic Biosorption of Arsenic onto Methi. 


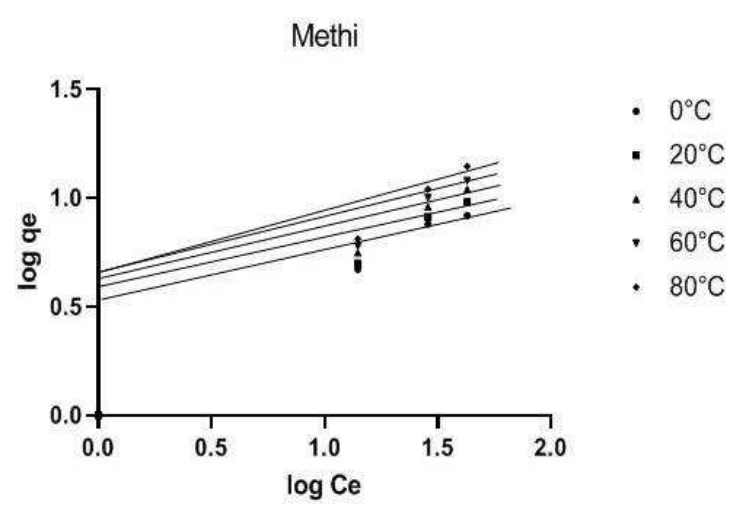

Figure 7. Arsenic removal by Freundlich isotherm.

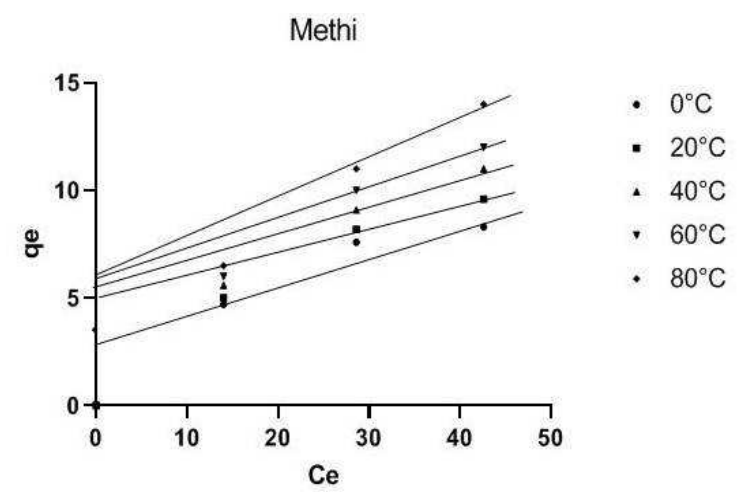

Figure 8. Temkin Isotherm for Arsenic Removal on Fenugreek Powder.

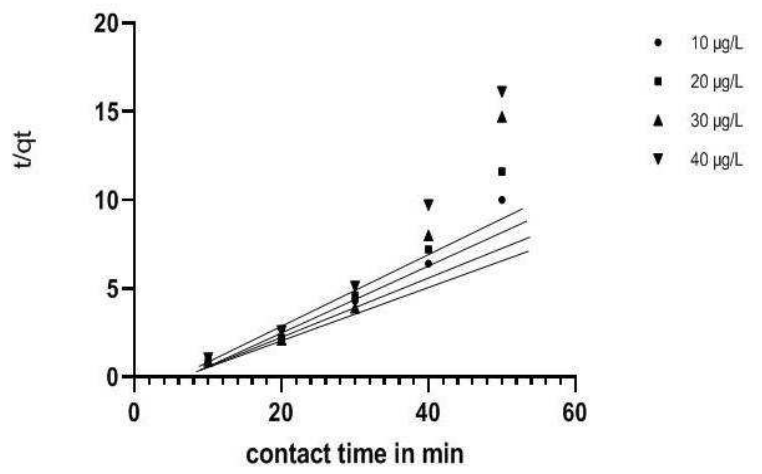

Figure 9. Pseudo-first order kinetic plot for Arsenic on Fenugreek powder.

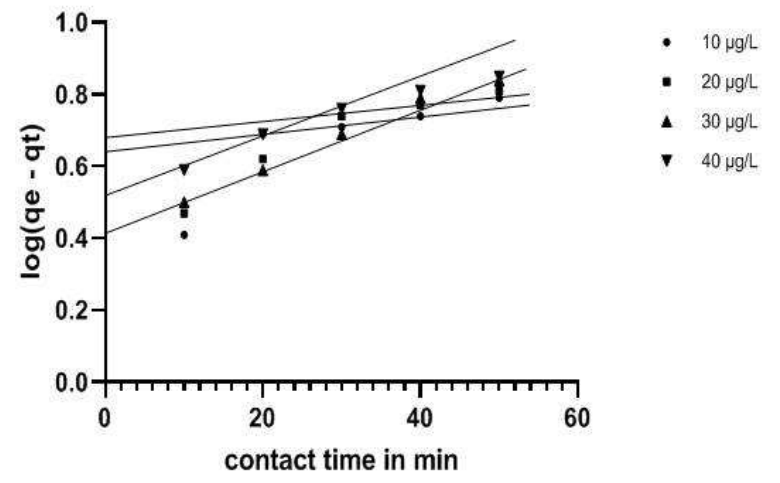

Figure 10. Pseudo-second order kinetic for Arsenic on Fenugreek powder.

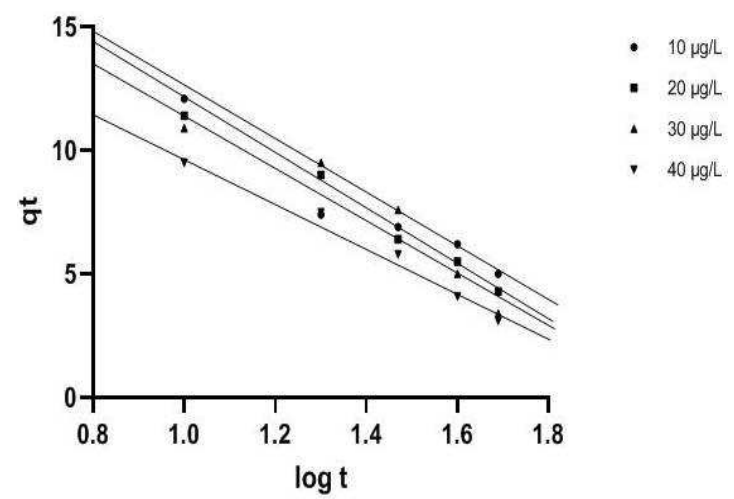

Figure 11. Elovich plot for Arsenic plot on Fenugreek powder.

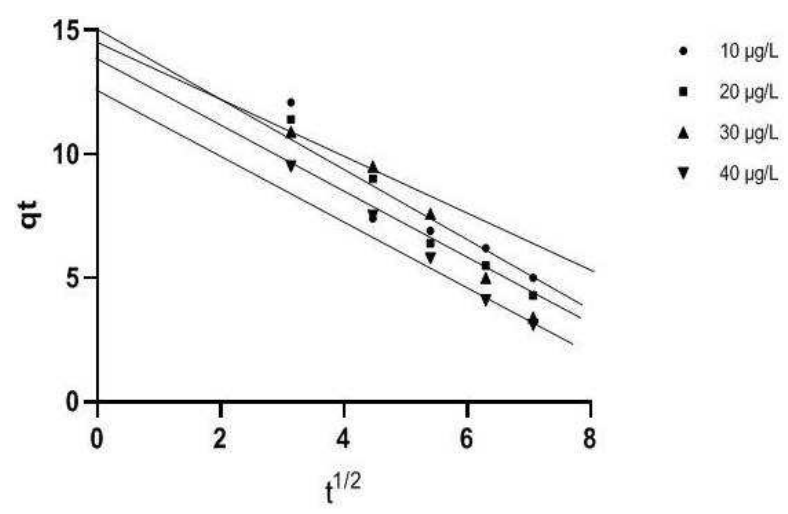

Figure 12. Intra particle diffusion for Arsenic on Fenugreek powder.

Methi

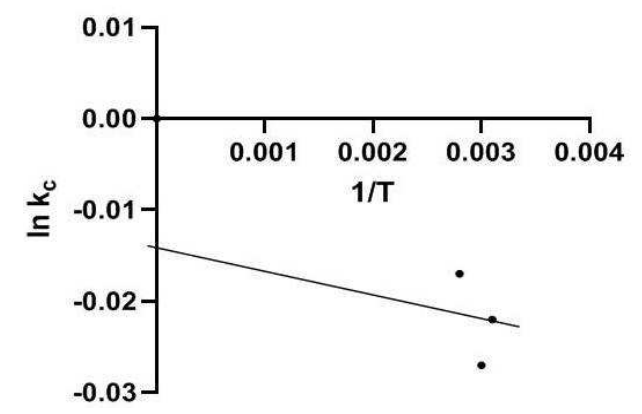

Figure 13. Relationship between $\ln \left(q_{e} / c_{e}\right)$ and $q_{e} \ln \left(K_{c}\right)$ and $1 / T$ for the removal.

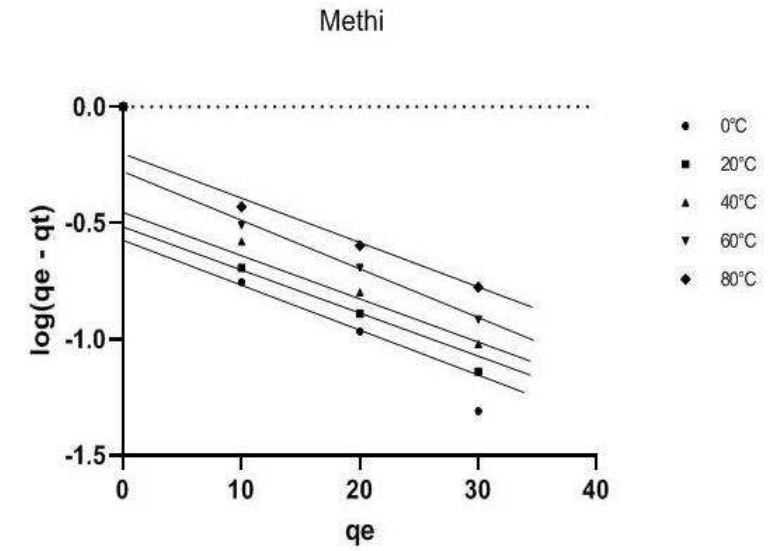

Figure 14. Relationship between for the removal of Arsenic of Arsenic. 


\section{Conclusion}

Based on few past reported scientific findings, fenugreek seed powder possesses the bioactive compounds that succour not only in the manufacture of healthy products, but also in the biosorption process for the expulsion of metals form the contaminated water which has been discussed in this review. Optimization of six physicochemical parameters, namely contact time of the biosorbent and the biosorbate, biosorbent dose, initial arsenic concentration, $\mathrm{pH}$ of the solution and temperature resulted $60 \%-70 \%$ arsenic removal. Isothrem models of Langumiur, Freundlich and Temkin study assured that the data is fit to Freundlich with greater correlation coefficient.

Thermdynamic, kinetic and equilibrium constants brought out the interpretation that arsenic biosospriotn onto fenugreek seed powder is endothermic, spontaneous and favourable at various temperatures.

Since, the research data established better epilogue with efficient report with parameters, fenugreek seed powder can be used as biosorbent for the metal removal from aqueous media.

\section{Acknowledgements}

I am ever thankful to Dr. B. B. V. Sailaja, the head of the Inorganic and Analytical Chemistry, Andhra university, Visakhapatnam, Dr. D. Sirisha for their contribution of guidance, support and zeal for the completion of this research paper and also to St. Ann's Degree College for women, Mehdipatnam, Hyderabad for providing me lab facilities with instrumentation and materials.

\section{References}

[1] Ishinishi N, Tsuchiya K, Vahter M, Fowler BA (1986) Handbook on the Toxicology of Metals. Elsevier, Amsterdam. Google Scholar.

[2] IARC (1982) Evaluation of the Carcinogenic Risk of Chemicals to Humans, Industrial Processes and Industries Associated with Cancer in Human. International Agency for Research on Cancer, Lyon. Google Scholar.

[3] ATSDR (2000) Toxicological Profile for Arsenic (update). U.S. Department of Health and Human Services, Atlanta. Google Scholar.

[4] IPCS (2001) Environmental Health Criteria 224. Arsenic and Arsenic Compounds, 2nd Ed. World Health Organization, Geneva. Google Scholar.

[5] Chatterjee. S, Variyar. S. P, Sharma. A, (2010), Bioactive lipid constituents of fenugreek Food Chem., 119, pp. 349-353.

[6] Deepa Basrur and Ishwara Bhat. J, (2017), “Activated Carbon from Fenugreek Seed: Characterization and Dyes Adsorption Properties". Iranian Journal of Energy \& Environment Journal, Homepage: www.ijee.net.

[7] Dhaif-Allah MAH, Taqui SN, Syed UT, Syed AA (2019) Development of sustainable acid blue 113 dye adsorption system using nutraceutical industrial Tribulus terrestrisspent. SN Appl. Sci 1 (4): 330.

[8] Mohammed A. H. Dhaif-Allah, Syed Noeman Taqui, Usman Taqui Syed, Akheel Ahmed Syed. (2020). "Kinetic and isotherm modeling for acidblue113 dye adsorption onto lowcost nutraceutical industrial fenugreek seed spent" Applied Water Science 10: 58 https://doi.org/10.1007/s13201-0201141-3.

[9] Gupta. S. S, and Bhattacharyya, K. G, (2008), "Immobilization of $\mathrm{Pb}(\mathrm{II}), \mathrm{Cd}(\mathrm{II})$ and $\mathrm{Ni}(\mathrm{II})$ ions on kaolinite and montmorillonite surfaces from aqueous medium," Journal of Environmental Management, vol. 87, no. 1, pp. 4658. View at: Publisher Site $\mid$ Google Scholar.

[10] Kannan, N. and Veemaraj, T., (2009). Removal of Lead (II) Ions by Adsorption onto Bamboo Dust and Commercial Activated Carbons-a comparative Study. E-Journal of Chemistry, 6 (2): 247-56, Available at: http://www.ejournals.net [Accessed 19 August 2011].

[11] Nomanbhay, S. M. and Palanisamy, K, (2005). Removal of heavy metal from industrial wastewater using chitosan coated oil palm shell charcoal. Electronic Journal of Biotechnology, Available at: http://www.ejbiotechnology.info/content/vol8/issue1/full/7/ [Accessed 4April 2011].

[12] Asma Saeed, Mehwish Sharif, Muhammad Iqbal, (2010), Application potential of grape fruit peel as dye adsorbent: Kinetics, equilibrium and mechanism of crystal violet adsorption, Journal of Hazardous Materials. 179: 564-572.

[13] Maedeh Mohammadi, Ali J. Hassani, Abdul Rahman Mohamed and Ghasem D. Najafpur, (2010), Removal of Rhodamine B from aqueous solution using palm shell based activated carbon: Adsorption and kinetic studies. Journal of Chemical and Engineering Data. 55: 5777-5785.

[14] Sharma, Y. C, (2011), Adsorption characteristics of a low-cost activated carbon for the reclamation of coloured effluents containing malachite Green. Journal of Chemical and Engineering Data. 56: 478-484.

[15] Ravindra Kumar Gautam, Ackmez Mudhoo, Mahesh Chandra Chattopadhya, (2013), Kinetic, equilibrium, thermodynamic studies and spectroscopic analysis of Alizarin Red S by removal by mustard husk. Journal of environmental Chemical Engineering. 1: 1283-1291.

[16] Eftekhari, S. Habibi-Yangjeh, A., Sohrabnezhad. S., (2010), Application of AIMCM-41 for competitive adsorption of methylene blue and rhodamine B: Thermodynmic and Kinetic studies. Journal of Hazardous Materials. 178 (1-3): 349-355.

[17] Yu Liu, (2009), Is the free energy change of Adsorption correctly calculated? Journal of Chemical and Engineering Data. 54: 1981-1985.

[18] Yu Liu, Hui Xu, (2007), Equilibrium thermodynamics and mechanism of $\mathrm{Ni}^{2+}$ biosorption by aerobic granules, Biochemical Engineering Journal 35: 174-182.

[19] Ramakrishanan. K, Namasivayam. C, (2011), Zinc chloride activated jatropha husk carbon for removal of phenol from water by adsorption; equilibrium and kinetic studies. Toxicology Environmental Chemistry 93 (6): 1111-1122. 